\title{
Excellent antibacterial activity of Slovak honeys on bacteria mostly infecting chronic wounds
}

\author{
Zemanova $\mathrm{M}^{1}$, Slobodnikova $\mathrm{L}^{2}$, Cambal $\mathrm{M}^{1}$, Labas $\mathrm{P}^{1}$ \\ 1st Department of Surgery, Faculty of Medicine, Comenius University in Bratislava and University \\ Hospital Bratislava, Bratislava, Slovakia. zemanova.maria@gmail.com
}

\begin{abstract}
INTRODUCTION AND AIM OF STUDY: Chronic wounds are commonly colonized by various bacterial species and colonization frequently turns into wound infection, severely impairing healing process. With increasing antimicrobial resistance, the antimicrobial treatment of chronic wounds may be extremely challenging. Rediscovery of old and forgotten antimicrobial therapeutic options, such as apitherapy, may contribute to solving the problem of incurable chronic wound infections. Aim of this study was to evaluate the antimicrobial properties of four kinds of Slovak honey from ecological beekeeping against the most common bacterial species contaminating and infecting chronic wounds, and to compare these antimicrobial activities with those of the approved medical-grade Manuka honey. The impact of honey sterilisation methods and long-lasting storage on the bactericidal activity was also examined.

MATERIAL AND METHODS: Antimicrobial activity of honey was detected against 7 bacterial collection strains by broth microdilution antimicrobial susceptibility test according to EUCAST. The results were statistically analysed by Fisher's exact test.

RESULTS AND CONCLUSIONS: Slovak ecologically produced honey samples demonstrated an excellent in vitro antibacterial activity, superior to the monofloral medical-grade Manuka honey activity. Neither the gamma-irradiation, nor the three-year-long storage had impact on the bactericidal activity of the tested honey (Tab. 4, Fig. 2, Ref. 53). Text in PDF www.elis.sk

KEY WORDS: chronic wounds, apitherapy, bacterial resistance, antibacterial activity, honey, medical-grade honey.
\end{abstract}

\section{Introduction}

Chronic wounds currently represent enormous medical, economic and social problem all over the world. They are defined as wounds which are not healed to full anatomical and functional integrity within 3 months (1).

According to The Wound Healing Society, there are four main groups of chronic wounds based on aetiology - venous ulcers, arterial insufficiency ulcers, diabetic foot ulcers and pressure ulcers (2).

These wounds are commonly colonized by various bacterial species, most commonly Pseudomonas aeruginosa, Staphylococcus aureus, Klebsiella pneumoniae, Acinetobacter baumannii (3), Escherichia coli, Enterococcus faecalis and Proteus mirabilis (4). Unfortunately, colonization frequently turns into wound infection, which severely impairs healing processes $(5,6)$ and if not treated

\footnotetext{
${ }^{1} 1$ st Department of Surgery, Faculty of Medicine, Comenius University in Bratislava and University Hospital Bratislava, Bratislava, Slovakia, and ${ }^{2}$ Institute of Microbiology, Faculty of Medicine, Comenius University in Bratislava and University Hospital Bratislava, Bratislava, Slovakia
}

Address for correspondence: M. Cambal, MD, PhD, MHA, MPH, 1st Department of Surgery, Faculty of Medicine, Comenius University in Bratislava and University Hospital Bratislava, Mickiewiczova 13, SK-813 69 Bratislava, Slovakia. successfully, may lead to several complications such as cellulitis, haemorrhage, or gangrene, leading to radical surgical procedures (such as extremity amputation), septicaemia, renal failure, or even death of the patient $(1,7,8)$.

Nowadays, in the era of increasing antimicrobial resistance among microorganisms, extensive research on new and more effective antibiotics is facilitated (9). On the other hand, alternative non-antibiotic treatments are applied, and the old and forgotten antimicrobial therapeutic options are being rediscovered.

The current available alternative topical treatment methods of chronic wounds include topical antiseptic agents, such as chlorine dioxide, sodium chloride, acetic acid, cadexomer iodine, cetrimide, chlorhexidine gluconate, povidone iodine, sodium hypochlorite, hydrogen peroxide, or silver dressings (10). The old, for years neglected non-antibiotic antimicrobial treatment methods are represented by phage therapy, $(7,11)$ maggot therapy $(12,13)$, phytotherapy (14) or apitherapy. Apitherapy includes therapeutic usage of bee products, such as honey, propolis, royal jelly or bee venom therapy $(15,16,17,18,19,20,21)$.

Honey is a unique natural compound. The definition of honey according to Codex Alimentarius is "natural sweet substance produced by honey bees from nectar of plants or from secretions of living parts of plants or excretions of plant sucking insects on living parts of plants, which the bees collect, transform by combining with specific substances of their own, deposit, dehydrate, 
store and leave in honey comb to ripen and mature". There are two known honey types according to Codex Alimentarius: blossom or nectar honey (honey coming from plant nectars) and honeydew honey (from excretions of insects that suck secretions of living parts of plants) (22).

Honey is the only compound digestible for all animal species, it is non-toxic and has long lifespan, and, what is from the therapeutic points of view the most important - for microorganisms it is not possible to grow in honey. Thanks to the complex composition of honey, microbes cannot develop resistance to it (23). This is what makes honey so unique in nature and what made honey to be one of the oldest natural remedies widely used for treatment of various diseases for thousands of years. In medical use, honey was preferred for its ability to stimulate immunity, to treat infection and after local application to heal wounds. In fact, honey is the oldest wound dressing material known to humans (18).

As the antibiotic era started, honey was forgotten and replaced by various antibiotics. But nowadays, in the era of worldwide spread of resistant and polyresistant microbial strains, honey gives the hope to solve the problem of incurable wound infections.

In fact, the contemporary ,western" medicine of Europe, New Zealand and Australia has already accepted honey as a medicine for treatment of various wounds, skin and mucosal lesions (18).

The positive effect of honey on wound healing is due to its ability to rapidly eliminate microorganisms colonizing and infecting wounds, its ability of wound deodorization, and painless autolytic debridement of wound bed. Through reducing oedema, honey improves circulation in capillaries and tissue oxygenation. It promotes tissue regeneration, stimulates angiogenesis, epithelisation and scar contraction. Its pain reducing effect has been proven as well. Due to its healing properties, honey significantly shortens healing time, reduces financial expenses and improves life quality of people suffering from chronic nonhealing wounds $(24,25,26,27,28,29)$.

Wound types successfully being treated by honey nowadays include infected wounds after trauma or surgery (e.g. amputation wounds, or abdominal postoperative wounds) (26), burns (30, 31), pressure sores (26), skin ulcers (32), diabetic foot ulcers (33), chronic venous ulcers (34), sickle cells ulcers (35), tropical ulcers (25), herpetic skin lesions (36), skin lesions from meningococcal septicaemia (37) or ophthalmic surface infections $(18,25)$.

In order to be used safely, honey has to be germ-free. Even if active and metabolising microorganisms cannot grow in honey, moulds, yeasts and spore-forming bacteria can persist in honey in the form of spores. In adequate conditions (e.g. in the wound cavity, digestive tract), spores can germinate and may start severe human infections $(38,39)$. Therefore, all medicine-grade honeys should be free of vital spores able to germinate, what should be obtained by a suitable sterilising process, not diminishing the antimicrobial and healing-stimulatory activity of honey $(18,40,41)$.

Up till now, several approved medical grade honey therapeutic preparations are available, such as manuka honey, kanuka honey, or Revamil honey (standardized, medical-grade honey, produced under controlled conditions in greenhouses) $(42,43)$.

However, in order to search for new sources of valuable biologically active honey with high antimicrobial activity, several studies were done on honey of various geographical origin (44, $45,46,47)$.

In accordance with these efforts, the aim of our study was to evaluate the antibacterial properties of four kinds of Slovak honey from ecological beekeeping and to compare them with an approved medicine-grade Manuka honey and with a commercial honeydew-honey antibacterial activity. Furthermore, the potential impact of honey sterilisation methods (filtration or gammairradiation) and the long-lasting storage of honey on bactericidal activity was examined.

\section{Materials and methods}

\section{The tested honey}

Six different types of honey were used in the tests (Tab. 1). The ecological Slovak honey (A-D), produced by Warré hives beekeeping of Apis mellifera in pollution-free area in north-west Slovakia, and harvested by pressing to minimalize the honey oxidation, was provided directly by the beekeeper. The commercial honeydew honey and the medicinal-grade Manuka honey were purchased in a retail-shop.

The honey samples were tested in their natural non-treated state, after filtration through bacteriological filter $(0.45 \mathrm{~mm}$; Merck Millipore Ltd., Ireland), and after gamma-irradiation. Gamma irradiation was performed in authorized company for radiation sterilization Bioster, Czech Republic, holder of ISO 9001, EN 46001 and ISO 11137/1,2,3 certificates. To evaluate the impact of the storage on antibacterial activity, the testing with the gammairradiated honey was repeated three years after the initial testing. Throughout the whole study, the honey was kept in cold, dry and dark conditions.

Tab. 1. The tested types of honey and the non-honey sugar solution control (the letters correspond with the honey labels in the Figures 1 and 2 ).

\begin{tabular}{cll}
\hline Figure label & The tested honey & Specification \\
\hline A & Ecological Honeydew Honey & Polyfloral honeydew honey, ecological, Slovakia \\
B & Ecological Summer Forrest Honey & Polyfloral nectar summer forest honey, ecological, Slovakia \\
C & Ecological Summer Honey Sediment & Polyfloral nectar summer honey sediment, ecological, Slovakia \\
D & Ecological Spring Meadow Honey & Polyfloral nectar spring meadow honey, ecological, Slovakia \\
E & Medical Manuka Honey & Medical-grade monofloral Manuka honey, Activon Tube, New Zealand \\
F & Commercial Honeydew Honey & Commercial polyfloral honeydew honey, Slovakia \\
G & Glucose Solution & "Non-honey" sugar solution \\
\hline
\end{tabular}


Tab. 2. Bacterial collection strains used in the study.

\begin{tabular}{lcc}
\hline Bacterial species & $\begin{array}{c}\text { Collection number } \\
\text { of strain }\end{array}$ & Note \\
\hline Staphylococcus aureus (1) & CCM 4750 & MRSA \\
Staphylococcus aureus (2) & CCM 4223 & MSSA \\
Enterococcus faecalis & CCM 4224 & \\
Pseudomonas aeruginosa & CCM 3955 & \\
Escherichia coli & CCM 3954 & \\
Klebsiella pneumoniae & CCM 4415 & \\
Proteus mirabilis & CCM 7188 & \\
\hline
\end{tabular}

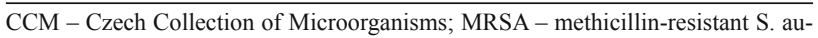
reus; MSSA - methicillin-susceptible $\mathrm{S}$. aureus

\section{The tested bacterial strains}

Collection strains of seven bacterial species, selected with respect to the spectrum of bacteria most commonly contaminating and infecting the human chronic wounds, were included into the study (Tab. 2). The strains were purchased from the Czech Collection of Microorganisms, Brno, Czech Republic.

\section{Antimicrobial activity testing}

Minimal inhibitory concentration (MIC) and minimal bactericidal concentration (MBC) of honey was evaluated using broth microdilution assay according to EUCAST, corresponding to ISO 20776-1:2019 (EUCAST, 2020) (48). Sterile U-shaped 96-wells microtiter plates (Roll s.a.s., Italy) and Mueller-Hinton Broth (OXOID UK) were used in the assay.

Prior to each of the test runs, aliquots of honey were freshly diluted in the antimicrobial susceptibility testing medium. Serial 1:1 geometric dilutions of honey, ranging from $50 \%(\mathrm{w} / \mathrm{V}$; equal to $500 \mathrm{mg} \cdot \mathrm{mL}^{-1}$ ) to $3.125 \%\left(\mathrm{w} / \mathrm{V}\right.$, equal to $\left.31.25 \mathrm{mg} \cdot \mathrm{mL}^{-1}\right)$, were prepared.

As a "non-honey" control, sugar solution containing glucose in amount corresponding to sugar content in honey $(80 \% \mathrm{w} / \mathrm{V})$ was used. The particular serial dilutions of honey and the glucose solution were applied into the corresponding wells of the microtiter plate in $100 \mathrm{~mL}$ volumes.

Bacterial inoculae were prepared in sterile physiologic solution from overnight bacterial cultures grown on blood agar. Bacterial suspensions were standardized using DEN-1 McFarland Densitometer (BioSan, Latvia) to reach $1.10^{6} \mathrm{CFU} \cdot \mathrm{mL}^{-1}$. The standardized suspensions were added to the corresponding microtiter wells in 10 $\mu \mathrm{L}$ aliquots (except to the sterility control wells, which contained bacteria-free medium or medium with the diluted honey samples only). Honey-free wells, inoculated by the tested bacteria, were used as growth control.

The MIC values were evaluated visually after an overnight incubation at $35{ }^{\circ} \mathrm{C}$. MICs were determined as the lowest concentration of honey that completely inhibited the growth of the tested bacterial strain. MBCs were determined by sub-culturing the samples from wells without visible signs of bacterial growth; solid culture medium free of honey was used. After an overnight incubation at $35{ }^{\circ} \mathrm{C}$, the MBCs were determined as the lowest concentration of the tested honey at which $99.9 \%$ of bacterial inoculum was inactivated. The non-treated honey and the honey sterilised by filtration or gamma-irradiation were parallelly tested in the same runs. Three independent runs were performed for each bacterial species.

\section{Analysis of results and their design}

The results were submitted to statistical analysis by Fisher's exact test; the graphs and tables design was performed by the computer program Microsoft Excel (MS-office 2019; Microsoft Corporation).

\section{Results and discussion}

Antibacterial activity of the tested honey samples

Antibacterial activities of four kinds of ecologically produced honey from pollution-free area of north-west Slovakia were compared with those of medical grade Manuka honey and commercial honeydew honey. Bacteria most commonly isolated from chronic wounds were used in the tests; they included two Staphylococcus aureus strains (one was methicillin-susceptible, the second was methicillin-resistant), and one strain of Escherichia coli, Pseudomonas aeruginosa, Enterococcus faecalis, Klebsiella pneumoniae and Proteus mirabilis (Tab. 2).

All the tested honey samples showed antibacterial inhibitory activity; however, some of them only at the highest (50\%) tested concentration (Fig. 1). Ecologically produced honeydew honey (honey A) and summer honey sediment (honey C) had significantly lower MICs to the majority of the tested bacterial strains in comparison with medical grade Manuka honey ( $p$ $\leq 0.1$ ). Concerning the bactericidal potential (Fig. 2), the best

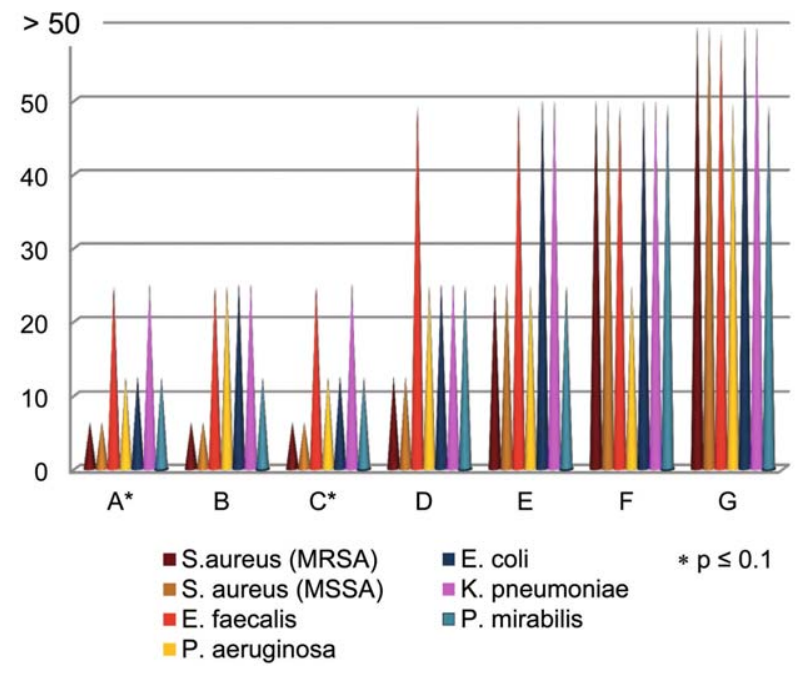

Fig. 1. Bacteriostatic activity of honey samples (expressed in \% w/V). A - Ecological Honeydew Honey, B - Ecological Summer Forrest Honey, C - Ecological Summer Sediment Honey, D - Ecological Spring Meadow Honey, E - Medical Manuka Honey, F-Commercial Honeydew Honey, G-Glucose Solution, MRSA - methicillin-resistant S. aureus MSSA - methicillin-susceptible S. aureus. 


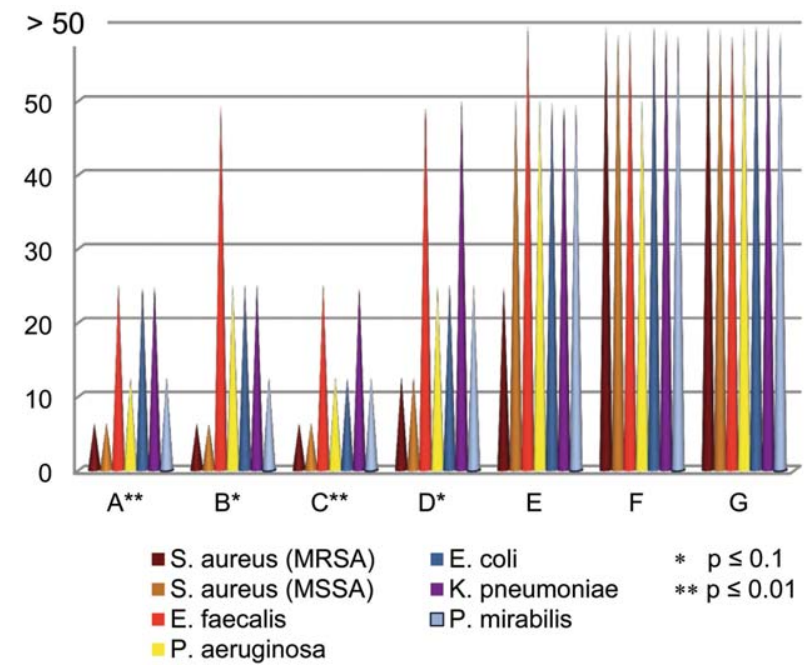

Fig. 2. Bactericidal activity of honey samples (expressed in \% w/V). A - Ecological Honeydew Honey, B - Ecological Summer Forrest Honey, C - Ecological Summer Sediment Honey, D - Ecological Spring Meadow Honey, E - Medical Manuka Honey, F-Commercial Honeydew Honey, G-Glucose Solution, MRSA - methicillin-resistant S. aureus, MSSA - methicillin-susceptible S. aureus.

results were detected again with ecologically produced honeydew honey (honey A) and summer honey sediment (honey C), which inactivated the tested $S$. aureus strains at the $6.3 \%$ concentration, $P$. aeruginosa and $P$. mirabilis at $12.5 \%$, E. coli at $25 \%$ and $12.5 \%$ concentration, respectively, and $E$. faecalis and $K$. pneumoniae at $25 \%$ concentration. The results were significantly superior $(\mathrm{p} \leq 0.01)$ in comparison with those received with medical grade Manuka honey. These two kinds of honey were followed by ecologically produced honey from mixed flower sources (summer forest - honey B, and spring meadow - honey D) with MBCs from $6.3 \%$ to $50 \%$ concentrations. These results were also significantly better $(\mathrm{p} \leq 0.1)$ than results obtained with Manuka honey, which inactivated the tested bacterial strains at concentrations from $25 \%$ to $>50 \%$. The less potent was commercial honeydew honey, with MBCs $>50 \%$ for all of the tested bacterial strains except to $P$. aeruginosa $(\mathrm{MBC}=50 \%)$. The glucose solution, when applied at the highest tested concentration, inhibited only the growth of $P$. aeruginosa and P. mirabilis, but had no bactericidal effect. The most susceptible to the tested honey samples were the strains of $S$. aureus, without respect to their susceptibility or resistance to methicillin. Gram-negative bacteria were, in general, less susceptible; the most susceptible from this bacterial group were P. aeruginosa and P. mirabilis. The tested $E$. faecalis strain showed susceptibility to the tested honey samples with values between those of staphylococci and the Gram-negative bacteria.

The final antibacterial activity of honey on various bacterial species of Gram-negative and Gram-positive bacteria is probably due to the complex nature of honey. First of all, honey contains approximately $80 \%$ of sugars, mainly glucose and fruc- tose. Sugars bind water and give hyperosmolar activity to honey. Due to this high osmolarity and hygroscopicity, honey draws the moisture out of the surrounding environment causing dehydration of bacteria, which are not able to grow in these conditions (49). Even if the impact of osmotic and hygroscopic activity of honey should to be considered in the final antibacterial activity of honey, this effect alone was not proved to be sufficient enough in inactivation of bacteria, as it is shown in our results with glucose solution in concentrations corresponding to sugar content of honey (sample G). Further, honey has a strong hydrogen peroxide activity. This activity is due to the content of glucose oxidase, which degrades glucose into gluconic acid, with hydrogen peroxide continuously formed as a secondary product, even if honey is being diluted. The antimicrobial activity of honey is also attributed to its low acidity. The gluconic acid, formed in honey during degradation reactions of glucose, yield the final $\mathrm{pH}$ between 3.2 and 4.5, which is inappropriate for growth of the majority of bacteria. Phytochemical plant products (e.g. monophenolic and polyphenolic compounds, or flavonoids), methylglyoxal (the conversion compound of dihydroxyacetone, found in the nectar of Manuka flowers), and antimicrobial peptides of bee origin (such as bee-derived defensin-1) belong to the last proposed antimicrobial tools of honey. All these compounds act as non-peroxide antimicrobial factors (18, 23, 49). The honey composition and its antibacterial activity is dependent on the floral origin of honey, geographical origin, climate conditions, way of beekeeping, way of honey process-

Tab. 3. Impact of sterilisation methods (filtration and gamma-irradiation) on antibacterial activity of honey samples (MBCs, expressed in $\left.\mu \mathrm{g} . \mathrm{mL}^{-1}\right)$.

\begin{tabular}{lccccc}
\hline Bacterial species & Honey A & Honey B & Honey C & Honey D & Treatment \\
\hline S. aureus (1) & 62.5 & 62.5 & 62.5 & 125 & n.a. \\
& 62.5 & 62.5 & 62.5 & 125 & GI \\
& 125 & 125 & 125 & 250 & BF \\
\hline S. aureus (2) & 62.5 & 62.5 & 62.5 & 125 & n.a. \\
& 62.5 & 62.5 & 62.5 & 125 & GI \\
\hline E. faecalis & 125 & 250 & 125 & 250 & BF \\
& 250 & 500 & 250 & 500 & n.a. \\
& 250 & 500 & 250 & 500 & GI \\
\hline P. aeruginosa & $>500$ & $>500$ & 500 & $>500$ & BF \\
& 125 & 250 & 125 & 250 & n.a. \\
& 125 & 250 & 125 & 250 & GI \\
\hline E. coli & 250 & 500 & 250 & 500 & BF \\
\hline & 250 & 250 & 125 & 250 & n.a. \\
& 250 & 250 & 125 & 250 & GI \\
\hline K. pneumoniae & 500 & 500 & 250 & 500 & BF \\
& 250 & 250 & 250 & 500 & n.a. \\
& 250 & 250 & 250 & 500 & GI \\
\hline P. mirabilis & 500 & 500 & 500 & 500 & BF \\
& 125 & 125 & 125 & 250 & n.a. \\
& 125 & 125 & 125 & 250 & GI \\
& 250 & 250 & 125 & 500 & BF
\end{tabular}

A-Ecological Honeydew Honey; B - Ecological Summer Forrest Honey; C - Ecological Summer Sediment Honey; D - Ecological Spring Meadow Honey; n.a. - no treatment applied; BF - filtration through bacteriologic filter; GI - gamma irradiation; for the bacterial strains characteristics see the Table 2 
Tab. 4. Impact of honey storage on antibacterial activity (MBCs, expressed in $\mu$ g.mL $\left.\mathrm{L}^{-1}\right)$.

\begin{tabular}{lccccc}
\hline Bacterial species & Honey A & Honey B & Honey C & Honey D & Testing \\
\hline S. aureus (1) & 62.5 & 62.5 & 62.5 & 125 & Time "0" \\
& 62.5 & 125 & 62.5 & 125 & +3 years \\
\hline S. aureus (2) & 62.5 & 62.5 & 62.5 & 125 & Time "0" \\
& 62.5 & 125 & 62.5 & 125 & +3 years \\
\hline E. faecalis & 250 & 500 & 250 & 500 & Time “0" \\
& 250 & 500 & 250 & 500 & +3 years \\
\hline P. aeruginosa & 125 & 250 & 125 & 250 & Time "0" \\
& 125 & 250 & 125 & 250 & +3 years \\
\hline E. coli & 250 & 250 & 125 & 250 & Time "0" \\
& 250 & 250 & 125 & 250 & +3 years \\
\hline K. pneumoniae & 250 & 250 & 250 & 500 & Time "0" \\
& 250 & 250 & 250 & 500 & +3 years \\
\hline P. mirabilis & 125 & 125 & 125 & 250 & Time "0" \\
& 125 & 125 & 125 & 250 & +3 years \\
\hline For the
\end{tabular}

For the legend see the Table 3.

ing and storage method $(50,51,52)$. Therefore, it is very difficult (if not impossible) to produce particular types of honey, which would be unique in all aspects of the active molecules content and the final biologic activity. This fact is supported also by our results - the most potent honey samples (ecologically produced honeydew honey and summer honey sediment) had probably more rich content of antimicrobial molecules and antibacterial mechanisms with assumed synergistic microbicidal activity. Furthermore, the ecological honeydew honey (honey A) was more effective probably due to the additional content of potentially active components of insect origin (mostly of aphids and of some of the scale insects), and the antibiotic products of plant origin synthesized in reaction to plant tissue damage caused by insects. All these compounds may be contained in honeydew - the excretion of plant-sap sucking insects (53). The honeydew is then collected by bees and processed into honey. The second most effective honey sample was the Ecological Summer Sediment Honey. Its excellent bactericidal activity was probably the result of higher concentrations of active molecules, as this type of honey contained highly concentrated honey sediment. To confirm this hypothesis, qualitative and quantitative analysis of the major antibacterial compounds in the tested honey samples will be performed during the further study. The higher bactericidal effectivity of Slovak ecological honey samples used in our study may also point to the role of the beekeeping method (Warré hives are assumed to give more natural conditions for bee life than the other types of hives) (51), to the geographical impact on the honey quality (50) and to the better performance of polyfloral kinds of honey in comparison with monofloral honey (such as Manuka honey) (52).

\section{Impact of honey sterilisation on antibacterial activity}

During the apitherapy, the honey must be applied directly into the treated wound or skin defect; therefore, it is inevitable to guarantee its germ-free state. The risk for patient treated by apitherapy may impose the contamination of honey by bacterial of fungal spores. At the same time, the process of honey sterilisation must keep untouched the antimicrobial and heeling properties of honey. In our study, two ways of honey sterilisation were selected - filtration through bacteriologic filter and gamma-irradiation. Filtration requires that the honey be available in the form of solution. Medicinal application of honey in the form of solution may be useful in the patients treated by wound or infected body-cavities irrigation. The necessity to use freshly dissolved honey may be considered as a great disadvantage of such application, as it is a time- and work-consuming process, requiring sterile conditions. Moreover, if the honey was once diluted, it cannot be stored for any later applications. On the other hand, gamma-irradiation allows usage of concentrated honey, which can be long-lastingly stored and later used either in its concentrated form or in solution. The effect of these two sterilisation procedures on the honey antibacterial activity is shown in the Table 3.

Filtration, in general, increased the MBC values of the honey samples by one dilution. Due to the high complexity of honey, it is highly possible that some of the components with antibacterial activity were bound to the filter membrane during the honey filtration. On the other hand, the gamma irradiation process had no effect on antibacterial activity of the tested honey samples, and seems to be a superior sterilising procedure.

\section{Impact of honey storage on antibacterial activity}

Production of medicinal-grade honey requires a lot of time, labour and supplementary equipment. Moreover, the apitherapy is usually not provided as a single treatment. Therefore, it is important to be sure, that the honey will not lose its biological activities during storage. In our study, evaluation of the impact of long-lasting honey storage on the honey antibacterial properties was performed with honey samples sterilised by gamma-irradiation. The samples were re-tested for their bactericidal activity after three years storage at cold $\left(4\right.$ to $\left.6{ }^{\circ} \mathrm{C}\right)$ and dark place in closed containers to prevent the contact with air. All the tested honey samples preserved their antibacterial activity even after three-year storage and (with a few exceptions) no increase in MIC/MBC values was detected; the results are shown in the Table 4. One-fold dilution increase of the MBC values was detected only in the case of the Ecological Summer Forrest Honey (honey B) against both of the tested S. aureus strains.

\section{Conclusions}

Slovak ecologically produced honey of polyfloral origin demonstrated an excellent in vitro antibacterial activity against bacteria commonly colonising and infecting chronic wounds. This activity was significantly superior to the monofloral medicalgrade Manuka honey and to the commercial honeydew honey. Gamma-irradiation did not influence the bactericidal activity of honey, neither did it the three years-long storage in cold, dry and dark conditions.

The highest therapeutic potential was presented by the samples of Slovak ecologically produced honeydew honey and summer honey sediment. They seem to be the most suitable candidates for a medical-grade honey preparation for chronic wounds topical 
treatment as a bio-alternative, especially for patients in whom other approved treatment methods were not effective. Supportive clinical studies are necessary prior to their introduction to the therapeutic armamentarium.

\section{References}

1. Jarbrink K, Ni G, Sonnergren H et al. Prevalence and incidence of chronic wounds and related complications: a protocol for a systematic review. Syst Rev 2016; 5 (1): 152.

2. The Wound Healing Society. Chronic wound care guidelines. Abridged version. 2007.https://woundheal.org/files/2017/final_pocket_guide_treatment.pdf. Accessed 14 Aug 2020.

3. Moghadam MT, Khoshbayan A, Chegini Z, Farahani I, Shariati A. Bacteriophages, a new therapeutic solution for inhibiting multidrugresistant bacteria causing wound infection: Lesson from animal models and clinical trials. Drug Des Devel Ther 2020; 14: 1867-1883.

4. Tzaneva V, Mladenova I, Todorova G, Petkov D. Antibiotic treatment and resistance in chronic wounds of vascular origin. Clujul Med 2016; 89(3): 365-370.

5. Zhou J, Yao D, Qian Z, Hou S, Li L, Jenkins ATA, Fan Y. Bacteriaresponsive intelligent wound dressing: Simultaneous in situ detection and inhibition of bacterial infection for accelerated wound healing. Biomaterials 2018; 161: 11-23.

6. Loesche M, Gardner SE, Kalan L et al. Temporal stability in chronic wound microbiota is associated with poor healing. J Invest Dermatol 2017; 137 (1): 237-244.

7. Pinto AM, Cerqueira MA, Bañobre-Lópes M, Pastrana LM, Sillankorva S. Bacteriophages for chronic wound treatment: from traditional to novel delivery systems. Viruses 2020; 12 (2): 235.

8. Grey JE, Enoch S, Harding KG. Wound assessment. BMJ 2006; 332 (7536): 285-288.

9. Koren J, Hubenakova Z, Ozaee E, Markuskova B, Lichvarikova A. Emergence of extended-spectrum $\beta$-lactamase (ESBL) and/or carbapenemase producing Enterobacteriaceae (CPE) and their antimicrobial resistance. Bratisl Med J 2019; 120 (12): 935-940.

10. Lipsky BA, Hoey Ch. Topical antimicrobial therapy for treating chronic wounds. CID 2009; 49: 1541-1549.

11. Oliveira A, Ribeiro HG, Silva AC et al. Synergistic antimicrobial interaction between honey and phage against Escherichia coli biofilms. Front Microbiol 2017; 8: 2407

12. Han G, Ceilley R. Chronic wound healing: a review of current management and treatments. Adv Ther 2017; 34: 599-610.

13. Bazalinski D, Kozka M, Karnas M, Więch P. Effectiveness of chronic wound debridement with the use of larvae of Lucilia Sericata. J Clin Med 2019; 8: 1845.

14. Shedoeva A, Leavesley D, Upton Z, Fan Ch. Wound healing and the use of medicinal plants. Evidence-Based Complementary and Alternative Medicine 2019; 2019: 2684108.

15. Majtan J. Apitherapy - the role of honey in the chronic wound healing process. Epidemiol Mikrobiol Imunol 2009; 58 (3):137-40.

16. Cornara L, Biagi M, Xiao J, Burlando B. Therapeutic Properties of Bioactive Compounds from Different Honeybee Products. Front Pharmacol 2017; 8: 412.
17. Pasupuleti VR, Sammugam L, Ramesh N, Gan SH. Honey, propolis, and royal jelly: a comprehensive review of their biological actions and health benefits. Oxid Med Cell Longev 2017; 2017: 1259510.

18. Yaghoobi R, Kazerouni A, Kazerouni O. Evidence of clinical use of honey in wound healing as an anti-bacterial, anti-inflammatory, antioxidant and anti-viral agent: a review. Jundishapur J Nat Pharm Prod 2013; 8 (3): 100-104.

19. Wagh VD. Propolis: a wonder bees product and its pharmacological potentials. Adv Pharmacol Sci 2013; 2013: 308249.

20. Fratini F, Cilia G, Mancini S, Felicioli A. Royal Jelly: an ancient remedy with remarkable antibacterial properties. Microbiological Research 2016; 192: 130-141.

21. El-Seedi H, Abd El-Wahed A, Yosri $\mathbf{N}$ et al. Antimicrobial properties of Apis mellifera's bee venom. Toxins 2020; 12 (7): 451.

22. Codex Standard for Honey, Codex STAN 12-1981, revisions 1997 and 2001, available on: http://www.fao.org/input/download/standards/310/ cxs_012e.pdf.

23. Kopal T. Med a hojenie rán. Dermatol prax 2016; 10 (2): 46-48.

24. Yilmaz AC, Aygin D. Honey dressing in wound treatment: a systematic review. Complementary Therapies in Medicine 2020; 51: 102388.

25. Molan PC. Potential of honey in the treatment of wounds and burns. Am J Clin Dermatol 2001; 2 (1): 13-19.

26. Hutton DJ. Treatment of pressure sores. Nurs Times 1966; 62 (46): $1533-1534$.

27. Kingsley A. The use of honey in the treatment of infected wounds:case studies. Br J Nurs 2001; 10 (22 Suppl): S13-6, S18, S20.

28. Vandamme L, Heyneman A, Hoeksema H, Verbelen J, Monstrey S. Honey in modern wound care: A systematic review. Burns 2013; 39 (8): 1514-1525.

29. Kefani PEP, Putra IBAD, Roosseno RRN. Honey clinically stimulates granulation and epithelization in chronic wounds: a report of two cases. Medical Journal of Indonesia 2018; 27: 62-68.

30. Ndayisaba G, Bazira $\mathbf{L}$, Habonimana $\mathbf{E}$ et al. Clinical and bacteriological results in wounds treated with honey. J Orthop Surg 1993; 7 (2): 202-204.

31. Subrahmanyam M. Topical application of honey in treatment of burns. Br J Surg 1991; 78 (4): 497-498.

32. Tovey FI. Honey and healing. J R Soc Med 1991; 84 (7): 447.

33. Wood B, Rademaker M, Molan PC. Manuka honey, a low cost leg ulcer dressing. N Z Med J 1997; 110: 107.

34. Holland LC, Norris JM. Medical grade honey in the management of chronic venous leg ulcers. Int J Surg 2015; 20: 17-20.

35. Okany C, Atimomo C, Akinyanju O. Efficacy of natural honey in the healing of leg ulcers in sickle cell anaemia. The Nigerian postgraduate medical journal 2004; 11: 179-181.

36. Al-Waili NS. Topical honey application vs. acyclovir for the treatment of recurrent herpes simplex lesions. Med Sci Monit 2004; 10 (8): MT94-8

37. Dunford C, Cooper RA, Molan PC. Using honey as a dressing for infected skin lesions. Nurs Times 2000; 96 (NTPLUS 14): 7-9.

38. Snowdon JA, Cliver DO. Microorganisms in honey. Int J Food Microbiol 1996; 31 (1-3): 1-26. 
39. Olaitan PB, Adeleke OE, Ola IO. Honey: a reservoir for microorganisms and an inhibitory agent for microbes. Afr Health Sci 2007; 7 (3): 159-165.

40. Molan PC, Allen KL. The effect of Gamma-irradiation on the antibacterial activity of Honey. J Pharm Pharmacol 1996; 48: 1206-1209.

41. Clark M, Adcock L. Honey for wound management: a review of clinical effectiveness and guidelines (Internet). Canadian Agency for Drugs and Technologies in Health 2018; available from: https://www.ncbi.nlm. nih.gov/books/NBK538361/.

42. Kwakman PH, Te Velde AA, de Boer L, Vandenbroucke-Grauls CM, Zaat SA. Two major medicinal honeys have different mechanisms of bactericidal activity. PLoS One 2011; 6 (3): e17709.

43. Bucekova M, Buriova M, Pekarik L, Majtan V, Majtan J. Phytochemicals-mediated production of hydrogen peroxide is crucial for high antibacterial activity of honeydew honey. Sci Rep 2018; 8 (1): 9061.

44. Ahmed S, Othman NH. Review of the medicinal effects of tualang honey and a comparison with manuka honey. Malays J Med Sci 2013; 20 (3): 6-13.

45. Ewnetu Y, Lemma W, Birhane N. Synergetic antimicrobial effects of mixtures of ethiopian honeys and ginger powder extracts on standard and resistant clinical bacteria isolates. Evid Based Complement Alternat Med 2014; 2014: 562804.

46. Morroni G, Alvarez-Suarez JM, Brenciani A et al. Comparison of the antimicrobial activities of four honeys from three countries (New Zealand, Cuba, and Kenya). Front Microbiol 2018; 9:1378.
47. Ng WJ, Ken KW, Kumar RV, Gunasagaran H, Chandramogan V, Lee YY. In-vitro screening of Malaysian honey from different floral sources for antibacterial activity on human pathogenic bacteria. Afr J Tradit Complement Altern Med 2014; 11 (2): 315-318.

48. The European Committee on Antimicrobial Susceptibility Testing - EUCAST: Antimicrobial susceptibility testing. Available on-line: https://www.eucast.org/ast_of_bacteria/mic_determination. Accessed on 2nd of August, 2020.

49. Eteraf-Oskouei T, Najafi M. Traditional and modern uses of natural honey in human diseases: a review. Iran J Basic Med Sci 2013; 16: 731-742.

50. Tomczyk M, Tarapatskyy M, Dzugan M. The influence of geographical origin on honey composition studied by Polish and Slovak honeys. Czech Journal of Food Sciences 2019; 37 (4): 232-238.

51. Heaf D. Sustainable bee-friendly beekeeping with the Warré hive. Biomics 2016; 8 (1): 27-35.

52. Dezmirean DS, Marghitas LA, Chirila F et al. Influence of geographic origin, plant source and polyphenolic substances on antimicrobial properties of propolis against human and honey bee pathogens. Journal of Apicultural Research 2017; 56 (5): 588-597.

53. Zhu J, Zhu K, Li L et al. Proteomics of the honeydew from the brown planthopper and green rice leafhopper reveal they are rich in proteins from insects, rice plant and bacteria. Insects 2020; 11 (9): 582.

Received December 21, 2020. Accepted January 15, 2021. 